\title{
Ictus isquémico cerebeloso: a propósito de un caso
}

\author{
Cerebellar ischemic stroke: apropos a case
}

Mujer de 24 años sin antecedentes, fumadora de menos de 1 paquete de cigarrillos al día y consumidora de anticonceptivos orales. Acude a Urgencias por sensación de giro de objetos e inestabilidad de la marcha de unos días de evolución, con vómitos alimentarios profusos y cefalea hemicraneal izquierda. No hubo caídas en los días previos ni otra sintomatología previa al inicio de esta clínica. La exploración física mostraba aumento de la base de sustentación, ataxia de la marcha y un nistagmus horizontal bilateral.

Se realizó TC craneal (figura 1), donde se observa un área hipodensa triangular en hemisferio cerebeloso izquierdo, compatible con proceso isquémico. Se asocia otra lesión de aspecto heterogéneo y probable componente microquístico, sugestiva de proceso neoplásico. Dados los hallazgos, se decide ingreso hospitalario y tratamiento antiagregante (ácido acetilsalicílico 100 mg cada 24 h). Los estudios de laboratorio no mostraron alteraciones en bioquímica, hemograma o coagulación, siendo además normales las pruebas de autoinmunidad (ANA, anticuerpos anticardiolipina) y trombofilia (factor V Leiden, mutación G20210A del gen de protrombina, proteínas C y S). El estudio RMN (figura 2) confirma la lesión isquémica en el territorio de la arteria cerebelosa superior. Además, se ratifica la lesión quística asociada, con un contenido de densidad similar al líquido cefalorraquídeo, sin realce periférico pero con cierto grado de espongiosis. Plantea como primera posibilidad diagnóstica la existencia de espacios perivasculares gigantes (también denominados espacios de Virchow-Robin dilatados), que condicionarían efecto masa en las estructuras vasculares adyacentes. Esto explicaría la clínica neurológica y la lesión isquémica cerebelosa.

La paciente mejoró clínicamente hasta una recuperación ad integrum. Se mantuvo al alta antiagregación oral y se prohibieron el tabaco y el uso de anticonceptivos orales.

Los espacios perivasculares gigantes son dilataciones del espacio subaracnoideo que acompañan a las arterias intracraneales en su trayecto hacia el parénquima cerebral. Se clasifican según la localización en tipo I (alrededor de las arterias lenticuloestriadas), tipo II (a nivel de sustancia blanca subcortical) y tipo III (en línea media supra 0 infratentorial, como en el caso descrito). Suelen ser un hallazgo radiológico ${ }^{1}$, pero en ocasiones pueden producir sintomatología ${ }^{2,3}$ de tipo cefalea, comicialidad o episodios cerebrovasculares como en nuestra paciente, favorecido por la toma de anticonceptivos y el tabaquismo. En los casos que se produce hidrocefalia obstructiva sintomática, la cistoventriculostomía mediante catéter podría plantearse como una opción terapéutica eficaz, realizando derivación peritoneal posterior para evitar la recurrencia de hidrocefalia ${ }^{4,5}$.

\section{Bibliografía}

1. Mathias J. et al. Giant cystic widening of Virchow-Robin Spaces: an anatomofunctional study. Am J Neuroradiol 28: 1523-25, 2007.

2. Marnet D. et al. Dilatation of Virchow-Robin perivascular spaces (types III cerebral lacunae): radio-clinical correlations. Rev Neurol (Paris); 163:5, 561-571, 2007.

3. Gronier S, Ayrignac X, Lamy C, Honnorat J, Thomas P, Lebrun-Frenay C, Labauge P. Symptomatic giant Virchow-Robin spaces. Rev Neurol 169: 898-902, 2013.

4. House P, Salzman K, Osborn A, MacDonald J, Jensen R, Couldwell W. Surgical considerations regarding giant dilations of the perivascular spaces. J Neurosurg 100: 820-824, 2004.

5. Roelz R, Egger K, Reinacher P. Giant perivascular spaces causing hemiparesis successfully treated by cystoventriculoperitoneal shunt. Br J Neurosurg, 29: 100-102, 2014

\section{Diagnóstico: Espacios perivasculares gigantes como causa de ictus isquémico cerebeloso.}

\author{
Pablo López Matoㅁ, Diego Rodríguez Gómez² \\ ${ }^{1}$ Servizo de Medicina Interna. ${ }^{2}$ Servizo de Neuroloxía. \\ Complexo Hospitalario Universitario de Ourense (CHUO
}

Figura 1. TC craneal realizado en Urgencias, donde se visualiza hipodensidad a nivel de cerebelo (asterisco), sugestiva de proceso isquémico. Se observa también una lesión heterogénea próxima al asta occipital izquierda del III ventrículo (flecha).

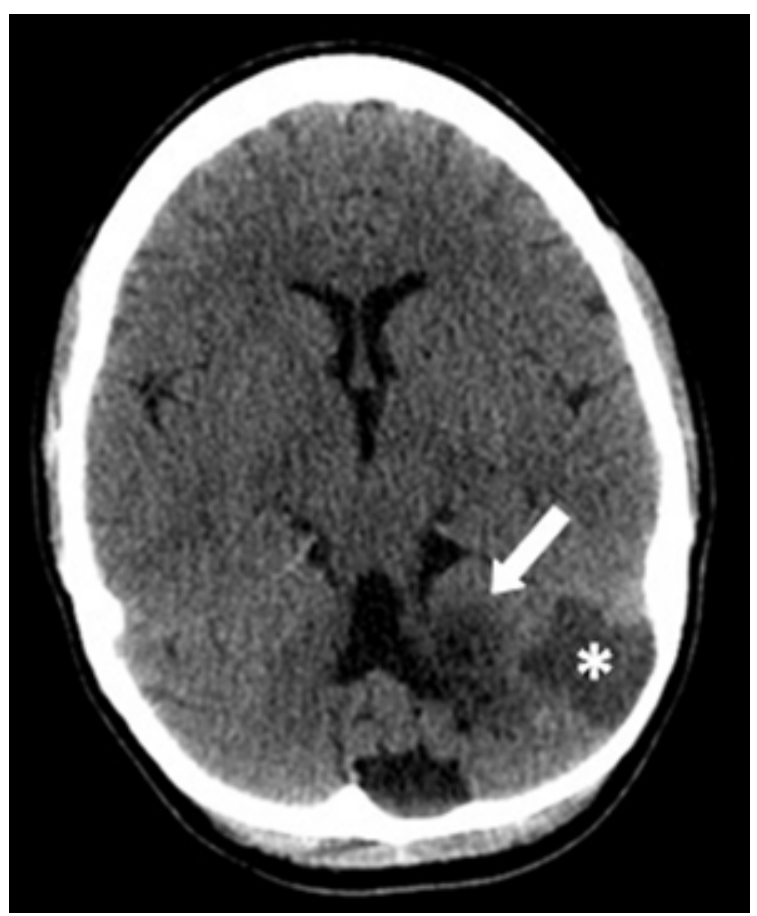

Figura 2. RMN cerebral en secuencia FLAIR. Además de apreciarse la afectación isquémica (asterisco), se confirma la naturaleza microquística del posible proceso tumoral (flecha), planteando los espacios perivasculares gigantes como una de las posibilidades etiológicas

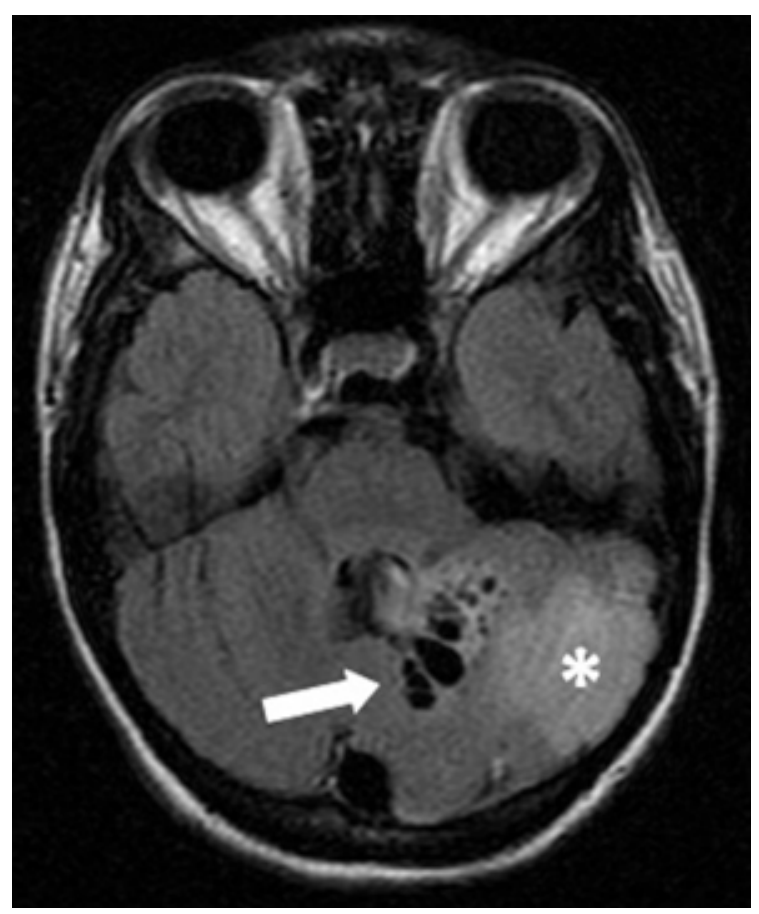

